\title{
POSITIVE SOLUTIONS FOR A SYSTEM OF $p$-LAPLACIAN BOUNDARY VALUE PROBLEMS
}

\author{
JIAFA XU*, DONAL O'REGAN**,*** AND KEYU ZHANG**** \\ ${ }^{*}$ School of Mathematical Sciences, Chongqing Normal University, Chongqing 401331, China \\ E-mail: xujiafa292@sina.com and jiafaxu@sina.cn \\ ** School of Mathematics, Statistics and Applied Mathematics, National University of Ireland \\ Galway, Ireland \\ ***NAAM Research Group, Department of Mathematics, King Abdulaziz University, Saudi Arabia \\ E-mail: donal.oregan@nuigalway.ie \\ ****Department of Mathematics, Qilu Normal University, Jinan 250013, Shandong, China \\ E-mail: keyu_292@163.com
}

Abstract. In this paper, we investigate the existence of positive solutions for a system of fourth order $p$-Laplacian boundary value problems

$$
\left\{\begin{array}{l}
-\left(\left(-x^{\prime \prime \prime}\right)^{p-1}\right)^{\prime}=f\left(t, x, x^{\prime}, y, y^{\prime}\right), t \in[0,1] \\
-\left(\left(-y^{\prime \prime \prime}\right)^{p-1}\right)^{\prime}=g\left(t, x, x^{\prime}, y, y^{\prime}\right), t \in[0,1] \\
x(0)=x^{\prime}(1)=x^{\prime \prime}(0)=x^{\prime \prime \prime}(1)=0 \\
y(0)=y^{\prime}(1)=y^{\prime \prime}(0)=y^{\prime \prime \prime}(1)=0
\end{array}\right.
$$

where $p>1, f, g \in C\left([0,1] \times \mathbb{R}^{+} \times \mathbb{R}^{+} \times \mathbb{R}^{+} \times \mathbb{R}^{+}, \mathbb{R}^{+}\right)\left(\mathbb{R}^{+}:=[0, \infty)\right)$. Under some new general conditions on $f$ and $g$, we use the fixed point index to establish two existence theorems for the above system. The interesting point lies in the fact that the nonlinear term $f, g$ can be allowed to depend on the first derivative of the unknown functions, and this derivative dependence in systems is seldom considered in the literature.

Key Words and Phrases: $p$-Laplacian equation; positive solution; fixed point index; derivative dependence.

2010 Mathematics Subject Classification: 34B18, 47H07, 47H11, 45M20, 26D15.

Acknowledgement. This research is supported by National Science Fund for Young Scholars of China (Grant No.11601048), Natural Science Foundation of Chongqing (Grant No.cstc2016jcyjA0181), the Science and Technology Research Program of Chongqing Municipal Education Commission (Grant No.KJ1703050), Natural Science Foundation of Chongqing Normal University (Grant No.15XLB011).

\section{REFERENCES}

[1] L. Cheng, W. Liu, Q. Ye, Boundary value problem for a coupled system of fractional differential equations with p-Laplacian operator at resonance, Electron. J. Diff. Equ., 2014(2014), no. 60, $1-12$. 
[2] W. Jiang, Solvability for a coupled system of fractional differential equations at resonance, Nonlinear Anal. Real World Appl., 13(2012), no. 5, 2285-2292.

[3] J. Jiang, L. Liu, Y. Wu, Positive solutions for p-Laplacian fourth-order differential system with integral boundary conditions, Discrete Dyn. Nat. Soc., 2012(2012), Article ID 293734, 19 pages.

[4] Y. Li, Z. Wei, Positive solutions for a coupled system of mixed higher-order nonlinear singular fractional differential equations, Fixed Point Theory, 15(2014), no. 1, 167-178.

[5] W. Yang, Positive solutions for nonlinear semipositone fractional q-difference system with coupled integral boundary conditions, Appl. Math. Comput., 244(2014), 702-725.

[6] N. Xu, W. Liu, Iterative solutions for a coupled system of fractional differential-integral equations with two-point boundary conditions, Appl. Math. Comput., 244(2014), 903-911.

[7] Z. Yang, Positive solutions for a system of p-Laplacian boundary value problems, Comput. Math. Appl., 62(2011), no. 12, 4429-4438.

[8] J. Xu, Z. Yang, Positive solutions for a system of nth-order nonlinear boundary value problems, Electron. J. Qual. Theory Differ. Equ., 2011(2011), no. 4, 1-16.

[9] J. Xu, Z. Yang, Positive solutions for a system of generalized Lidstone problems, J. Appl. Math. Comput., 37(2011), no. 1-2, 13-35.

[10] J. Xu, Z. Yang, Three positive solutions for a system of singular generalized lidstone problems, Electron. J. Diff. Equ., 2009(2009), no. 163, 1-9.

[11] R. Precup, A vector version of Krasnosel'skii's fixed point theorem in cones and positive periodic solutions of nonlinear systems, J. Fixed Point Theory Appl., 2(2007), no. 1, 141-151.

[12] G. Infante, M. Maciejewski, R. Precup, A topological approach to the existence and multiplicity of positive solutions of $(p, q)$-Laplacian systems, arXiv:1401.1355.

[13] Y. Ding, J. Xu, X. Zhang, Positive solutions for a 2nth-order p-Laplacian boundary value problem involving all derivatives, Electron. J. Diff. Equ., 2013(2013), no. 36, 1-14.

[14] D. Guo, V. Lakshmikantham, Nonlinear Problems in Abstract Cones, Academic Press, Orlando, 1988.

[15] I.A. Rus, A. Petruşel, M.A. Şerban, Weakly Picard operators: equivalent definitions, applications and open problems, Fixed Point Theory, 7(2006), no. 1, 3-22.

[16] I.A. Rus, A. Petruşel, G. Petruşel, Fixed Point Theory, Cluj University Press, 2008.

[17] D. O'Regan, N. Shahzad, R.P. Agarwal, Fixed point theory for generalized contractive maps on spaces with vector-valued metrics, Fixed Point Theory and Applications, (Eds. Y.J. Cho, J.K. Kim, S.M. Kang), Vol. 6, Nova Sci. Publ., New York, 2007, 143-149.

Received: August 28, 2014; Accepted: March 12, $201 \%$. 
